\title{
A comparative evaluation of dimensional stability of three types of interocclusal recording materials-an in-vitro multi-centre study
}

Sampath Kumar Tejo ${ }^{1}$, Anil G Kumar ${ }^{2}$, Vivekanand S Kattimani ${ }^{3,7^{*}}$, Priti D Desai ${ }^{4}$, Sandeep Nalla ${ }^{5}$ and Krishna Chaitanya $K^{6}$

\begin{abstract}
Background: The introduction of different interocclusal recording materials has put clinicians in dilemma that which material should be used in routine clinical practice for precise recording and transferring of accurate existing occlusal records for articulation of patient's diagnostic or working casts in the fabrication of good satisfactory prosthesis. In the era of developing world of dentistry the different materials are introduced for interocclusal record with different brand names because of this; the utility of the material is confusing for successful delivery of prosthesis with lack of in vitro or in vivo studies which will predict the property of the material with utility recommendations.
\end{abstract}

Purpose of the study: The aim of this multicenter research is to evaluate the time dependent linear dimensional stability of three types of interocclusal recording materials; which gives very clear idea to clinicians in regard to its usage in routine practice and recommendations for usage of the different materials. Also to find out ideal time for articulation of three types of interocclusal recording materials with accuracy.

Materials and method: Commercially available and ADA approved Polyether bite registration paste (Ramitec), Poly vinyl siloxane bite registration paste (Jetbite) and Zinc oxide eugenol (ZOE) bite registration paste (Super bite) were used in the study.

A stainless steel die was made according to modified American dental Associations (ADA) specification no. 19. Each one of the tested materials were manipulated according to manufacturers' instructions. The materials separated from die, 3-mins after their respective setting time, resulted in disks of standard diameter. Two parallel lines and three perpendicular lines reproduced on the surface. The distance between two parallel lines was measured at different time intervals i.e. 1 hour, 24, 48 and 72 hours by using travelling microscope (magnus) and compared with standard die measurements made according to ADA specification no.19 to find out the dimensional stability of these interocclusal recording materials. Total 120 samples were made for observation and results were subjected to statistical analysis. Statistical analysis was performed using analysis of variance (ANOVA) and then Tukey's Honestly Significant Difference (HSD) test for comparison among groups at the 0.05 level of significance. After statistical analysis of the data, results were obtained and analyzed for interpretation.

(Continued on next page)

\footnotetext{
* Correspondence: drvivekanandsk@gmail.com

${ }^{3}$ Department of oral and maxillofacial Surgery, Saraswati Dhanwantari Dental College and Hospital, Parbhani, Pathri road, NH222, Parbhani, Maharashtra, India

${ }^{7}$ Department of oral and maxillofacial Surgery, Saraswati Dhanwantari Dental College and Hospital, Parbhani, Pathri road, NH222, Parbhani, Maharashtra, India

Full list of author information is available at the end of the article
} 
(Continued from previous page)

Results: The results shows significant difference between the dimensional stability of all three material at different intervals with $\mathrm{p}$-value $<0.05$. Comparatively the polyether bite registration material showed less distortion with good dimensional stability compared to Poly vinyl siloxane bite (Jetbite), Zinc oxide eugenol(ZOE) bite (Super bite) at 1 hour, 24, 48, and 72 hours.

Conclusion: The dimensional stability decreased with increase in time and is influenced by both material factor and time factor. Polyether was found to be more dimensionally stable interocclusal recording material, which was followed by Silicone and Zinc oxide eugenol (ZOE). The dimensional stability of Polyether was good. Zinc oxide eugenol is dimensionally more unstable when compared with polyether and polyvinyl siloxane. We recommend that the polyether interocclusal records must be articulated within 48 hours and Polyvinylsiloxane interocclusal records must be articulated within 24 hours and the ZOE should be articulated within 1 hour to get a correct restoration to have very minimum distortion and maximum satisfaction without failure of prosthesis.

Keywords: Polyether bite, Poly vinyl siloxane bite, Zinc oxide eugenol (ZOE) bite, Dimensional stability, Interocclusal records

\section{Introduction}

The interocclusal record by various materials and methods will play a positive role in securing the desired occlusion in the fabrication of prostheses. Phillip pfaff in 1756 made the first interocclusal records using natural waxes [1-3]. Since then many materials and techniques have been evolved for recording interocclusal relationship. These materials are basically impression materials that have been modified to give better handling characteristics. These include impression plaster, Dental waxes, ZOE impression paste, acrylic resin, hydrocollides and newer one includes polyether and polyvinylsiloxane bite registration materials [2-9]. Since beginning of era of dentistry, the dental waxes and ZOE impression pastes are used till today as bite registration materials because of ease of manipulation and economically viable, as they are less time consuming and less skill dependent [5-7]. They have been adjudged as base materials for the development of newer materials and methods for recording interocclusal relations of teeth. Hence here it is used as control and comparative material with newly developed bite registration material.

Precise articulation of patient's diagnostic or working casts is a prerequisite for fabrication of prosthesis [1]. A clinically acceptable prosthesis should be in harmony with the existing stomatognathic system. Recording and transferring of accurate existing occlusal records is of prime importance for a successful restoration. Interocclusal recording of the relationship of the mandible to the maxilla is a simple but complex procedure. The inaccuracies attributed to the interocclusal records can be divided into three categories [8]: 1) The biologic characteristics of stomatognathic system, 2) Manipulation of the material, and 3) The properties of the interocclusal recording materials.

Manipulation of the material such as variations in the manner with which the dentist manages the patient and the material during the clinical phases. Of all the properties of the interocclusal recording materials, most important is the dimensional changes caused due to delay in carrying materials to distant laboratories or delay in articulation or remounting of casts play a key role. To solve all these problems we require an ideal interocclusal recording material which is dimensionally stable with passage of time.

Interocclusal recording materials like wax and zinc oxide eugenol are used since beginning. But introduction of newer elastomeric materials in market has put clinicians in dilemma for the selection and usage. These elastomeric materials are chemically similar to the impression materials that have been used for many years [9-14]. Modifications have been made by adding plasticizers and catalyst to provide different handling characteristics [2]. However, it remains unknown whether these modifications in the parent impression materials have altered their properties like dimensional stability [1]. Delayed articulation of patients casts can occur for various reasons [10-18] therefore, the dimensional stability of interocclusal recording materials is most important in multi setup as all the factors has to be considered and analyzed for the recommendation or conclusion.

The ideal requirements of materials to be used for bite registration are[1-3,5-7] 1)It should become rigid and exhibit minimal dimensional change after setting 2) It should have limited resistance before setting to avoid displacement of teeth or mandible during closure 3) It should produce accurate record of incisal and occlusal surface of the teeth 4) It should be easy to manipulate 5) It should not produce adverse effects on the tissues involved in procedure 6) It should allow easy verification.

An ideal material for interocclusal record allows the intraoral placement of restorations without extensive adjustments. In order to achieve this goal the use of 
interocclusal recording materials which are dimensionally stable is of paramount importance. Much work has not been done to judge the dimensional stability; which is needed over a period of time. So multicenter research has been done, to evaluate the time dependent linear dimensional stability of three types of interocclusal recording materials; which gives very clear idea to clinicians with regard to its usage in routine practice and also recommendations for usage of the different materials.

\section{Materials and method}

The following interocclusal recording materials were selected for the study;

1) Polyether bite registration paste (Ramitec, $3 \mathrm{M}$ ESPE, AG Dental Products, Germany).

2) Vinylpolysiloxane bite registration cream (Jet bite, Coltene Whaledent, swezerland).

3) Zinc-oxide eugenol bite registration paste. (Super bite, Bosworth Company, Skokie).

\section{Equipment}

1. Travelling microscope- (Figure 1).(Magnus, India)

2. Thermostat controlled water bath unit.

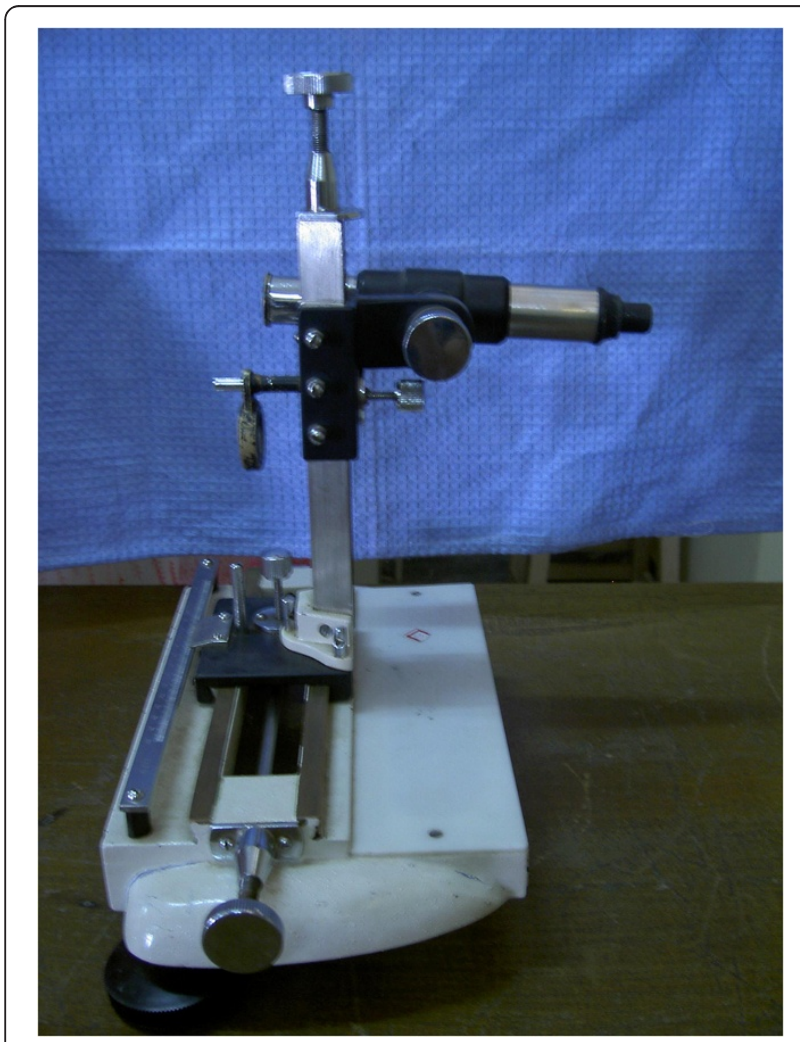

Figure 1 Travelling microscope.
Methods followed in this study have been discussed under the following headings:

The method chosen to compare the dimensional stability was as per the testing methodology of ADA specification no.19-for elastomeric impression materials. 1) Preparation of mold, 2) Selection and manipulation of materials, 3) Preparation of samples, 4) Measurement of the distance between lines for determining dimensional stability.

\section{Preparation of mold}

A study mold (Figure 2, Figure 3, Figure 4) was prepared according to revised American Dental Association specification no.19 for non-aqueous elastic dental impression materials. It consists of a ruled block (AA), test material mold (BB) and a riser (CC). All parts were made up of stainless steel. The ruled block was having three horizontal lines of different width; small Y-line $(24 \mu \mathrm{m})$, medium X-line $(57 \mu \mathrm{m})$ and a thick Z-line $(83 \mu \mathrm{m})$, and two vertical lines $C D$ and $C^{\mathrm{I}} \mathrm{D}^{\mathrm{I}}$ of $82 \mu \mathrm{m}$ each. The lines $C D$ and $C^{\mathrm{I}} \mathrm{D}^{\mathrm{I}}$ were separated from each other by $25 \mathrm{~mm}$ approx. The test mold was a cylinder of inner diameter $30 \mathrm{~mm}$ and depth of $6 \mathrm{~mm}$ to place the bite registration material. The riser was a stainless disk of diameter $29.9 \mathrm{~mm}$ and thickness of $3 \mathrm{~mm}$.

\section{Manipulation of polyether bite registration paste}

For Polyether bite (Ramitec E.S.P.E) required amount of equal lengths of pastes were dispensed on the mixing pad provided by the manufacturer. These two pastes were mixed together with stainless steel mixing spatula for 45 to 50 seconds to get a homogenous streak free mix. The mix was then collected on the mixing spatula and loaded in a plastic syringe provided by the manufacturer. The material was then spread on the surface of the die by taking precautions not to incorporate any air bubbles and a glass plate covered with polyethylene sheet and a weight of $500 \mathrm{~g}$ was placed over it. The material was allowed to set for 4-5 min in thermostatically controlled water bath to simulate mouth condition.

\section{Manipulation of polyvinyl siloxane bite registration material}

The Polyvinyl siloxane bite (Jet bite, coltene whaledent), was supplied in the form of cartridge containing base and accelerator paste. The cartridge along with mixing tip was attached to an auto-mixing gun. The material which expelled from the gun was uniformly spread over the surface of the die. A glass plate covered with polyethylene sheet was placed on the die over which a weight of $500 \mathrm{~g}$ was kept and allowed to set for 4-5 min in thermostatically controlled water bath to simulate mouth condition. 


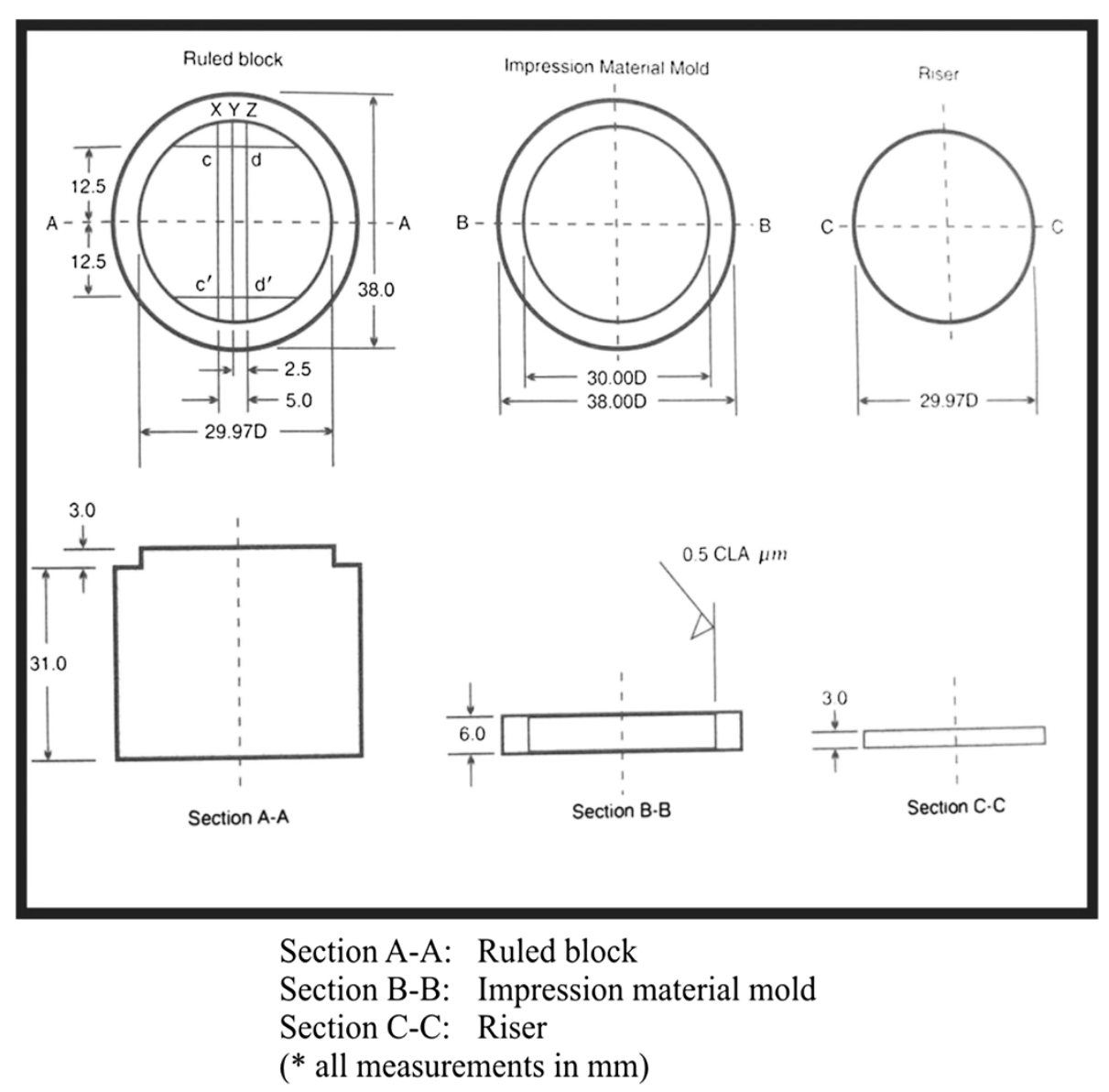

Figure 2 Schematic diagram of block reproduction.

\section{Manipulation of zinc oxide eugenol bite registration paste}

For Zinc oxide eugenol bite registration paste (Superbite), equal length of both base and catalyst pastes were dispensed on the cool glass slab. By using stainless steel mixing spatula, they were mixed in clockwise direction for 45 seconds to get a streak free homogenous mix. The material was then collected on the mixing spatula and by taking precautions to avoid incorporation of air bubbles; the mix was spread over the surface of the die. Subsequently a glass plate covered with polyethylene sheet and a weight of $500 \mathrm{~g}$ was placed over it and the material was allowed to set for 8 to 10 minutes in thermostatically controlled water bath to simulate mouth condition.

\section{Preparation of samples}

The whole assembly was then submerged in water bath of temperature $36 \pm 1^{0} \mathrm{C}$ resembling open mouth temperature. Each assembly remained in the bath for the setting time suggested by manufacturer, plus $3 \mathrm{~min}$ to ensure polymerization in case of elastomeric materials.
After removal from the water bath, the material was separated from the die by using the disk (riser). The excess flash was trimmed using a Bard Parker knife. Thus prepared specimens (Figure 5) were measuring $30 \mathrm{~mm}$ in diameter, $3 \mathrm{~mm}$ in thickness and had the lines $\mathrm{X}, \mathrm{Y}, \mathrm{Z}, \mathrm{CD}$ and $\mathrm{C}^{\mathrm{I}} \mathrm{D}^{\mathrm{I}}$ lines on it. Similarly, all the 30 bite registration record samples from each center were obtained. In between days of observation, the samples were stored in a moisture free polyethylene bags at room temperature of $28 \pm 2^{\circ} \mathrm{C}$.

\section{Observation of samples for dimensional stability}

The distance between the lines, $C D$ and $C^{\mathrm{I}} \mathrm{D}^{\mathrm{I}}$, reproduced on the samples, was measured at three different points $\mathrm{PP}^{\mathrm{I}}, \mathrm{QQ}^{\mathrm{I}}$ and $\mathrm{RR}^{\mathrm{I}}$ (i.e. at the intersections of these lines with the lines $\mathrm{XYZ}$ ) by using travelling microscope with $10 \mathrm{X}$ magnification. Three readings were obtained for each sample and the averages of these three values were noted. Likewise readings were made at different time intervals i.e.; 1 hour after removal of the material from the die, at 24 hours, at 48 hours and at 72 hours respectively for each of the samples. All the readings 


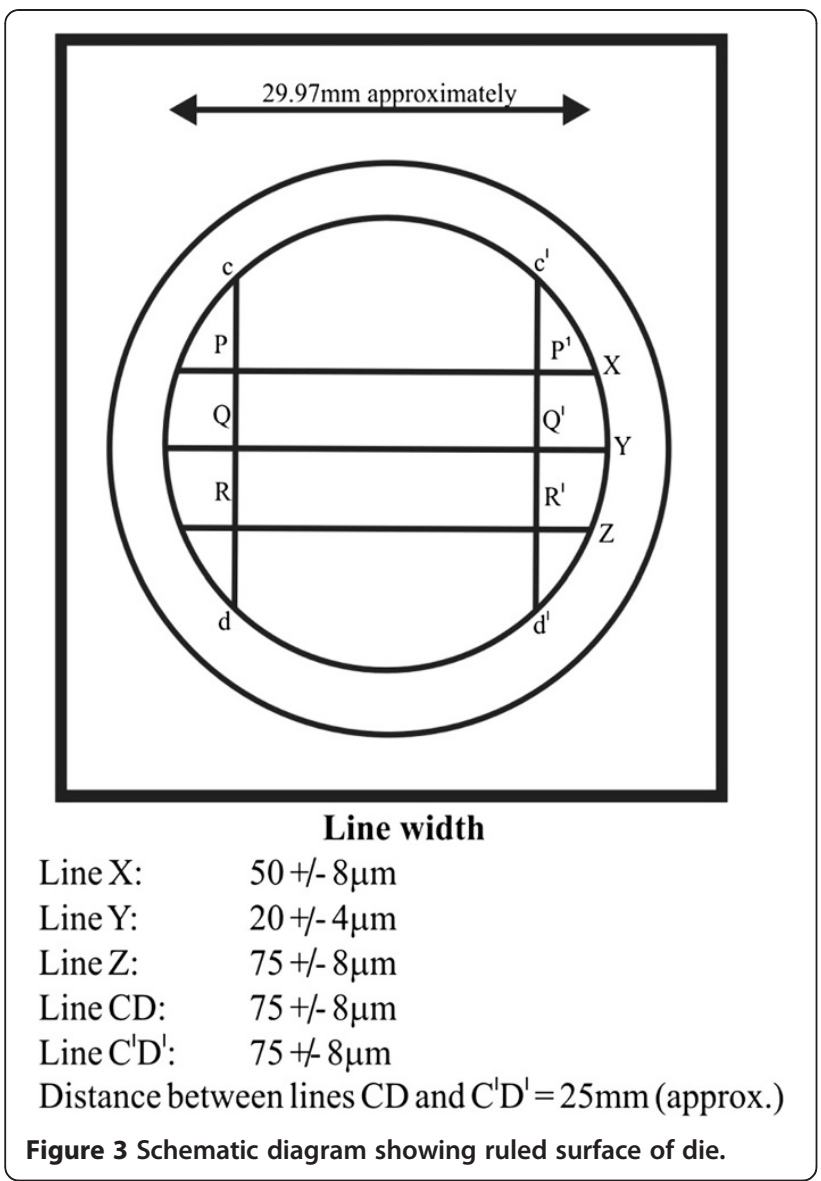

thus obtained were tabulated (Table 1) and subjected to statistical analysis for the comparison of dimensional stability of three interocclusal recording materials.

\section{Evaluation of dimensional change}

The change in the Dimension is calculated by using the formula

\section{Dimensional change $\%=(X-Y) x 100$}

Where $\mathbf{X}$ is the standard measurement $(\mu \mathrm{m})$ of $C D$ and $\mathrm{C}^{\mathrm{I}} \mathrm{D}^{\mathrm{I}}$ in the Die.

$\mathbf{Y}$ is the observed measurement $(\mu \mathrm{m})$ of $C D$ and $C^{I} D^{I}$ in the sample

Statistical analysis was performed using analysis of variance (ANOVA) and then Tukey's Honestly Significant Difference (HSD) tests for comparison among groups at the 0.05 level of significance.

The force of $5.564 \mathrm{n}$ (500 g external weight $+67 \mathrm{~g}$ glass plate) was applied during making of the interocclusal registration. This force was chosen because researchers showed that the force required to compensate initial resistance of interocclusal material to closure; varying between $0.5 \mathrm{n}$ to $13.8 \mathrm{n}$ [8]. During the interval period

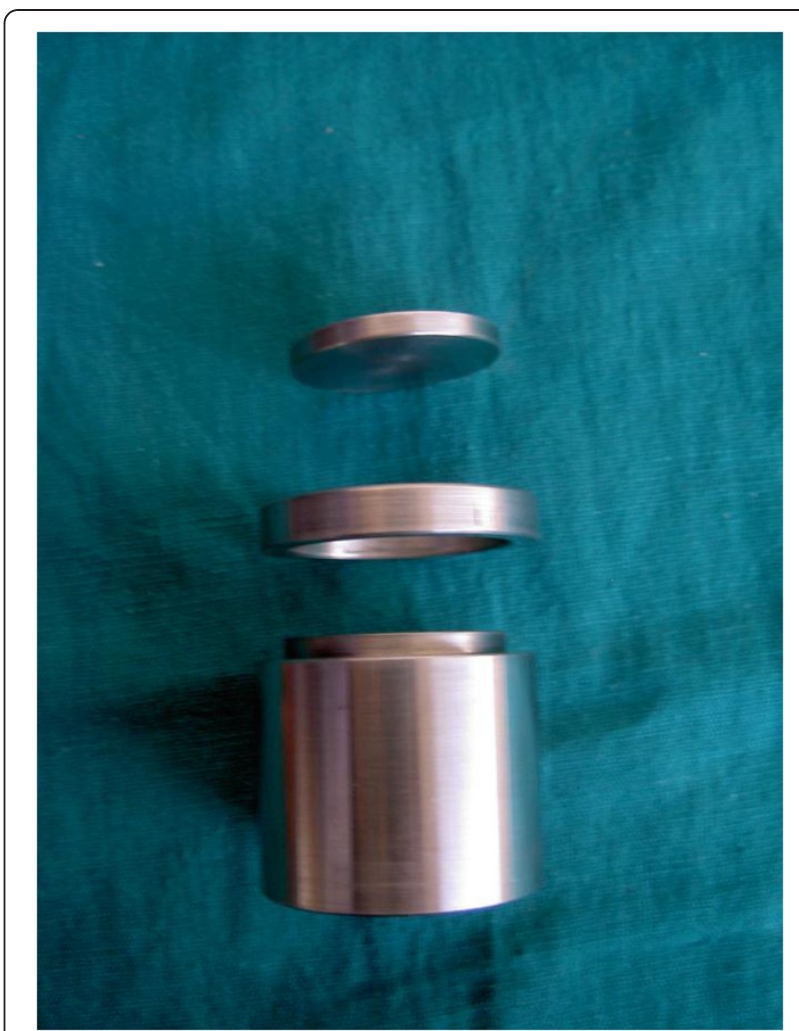

Figure 4 Master die with raiser.

of the study, all the specimens were stored in sealed dry polyethylene bags at room temperature $\left(28 \pm 2^{\circ} \mathrm{C}\right)$ as dimensional changes of elastomers can be reduced by storage in a sealed dry container and at room temperature [10-17].

The linear dimensional change of the interocclusal recording materials over time was measured in this study. The time intervals used in the study were selected

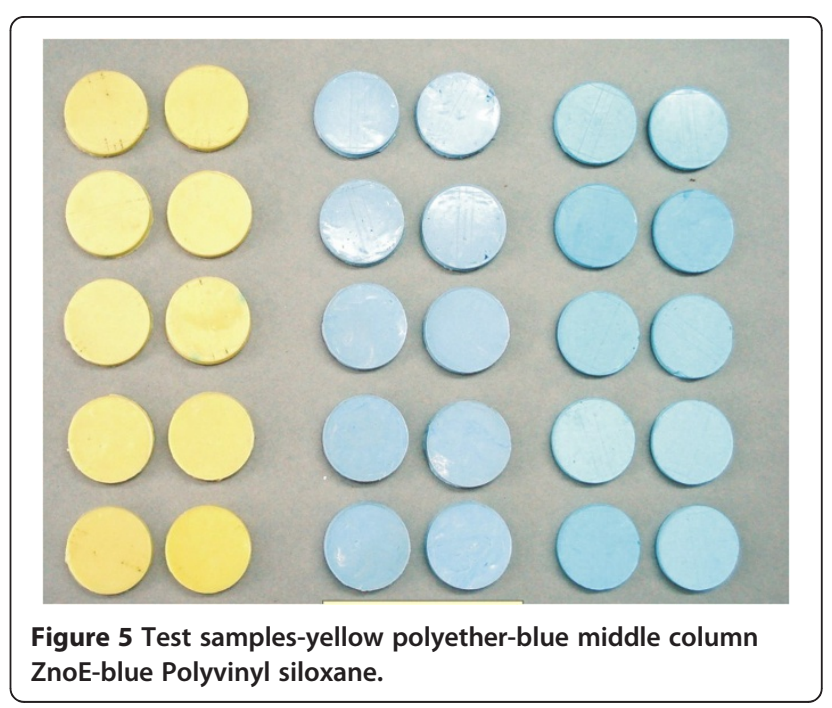


Table 1 Showing the master chart of average data of four centers obtained during study

\begin{tabular}{|c|c|c|c|c|c|}
\hline \multirow[t]{2}{*}{ Materials } & \multirow[t]{2}{*}{ sample no. } & \multicolumn{4}{|c|}{ Dimensional stability : mean distance between lines $(\mathrm{mm})$} \\
\hline & & 1Hour & 24Hours & 48Hours & 72 Hours \\
\hline \multirow[t]{10}{*}{ Polyether } & 1 & 24.742 & 24.728 & 24.735 & 24.713 \\
\hline & 2 & 24.791 & 24.79 & 24.756 & 24.74 \\
\hline & 3 & 24.681 & 24.644 & 24.663 & 24.594 \\
\hline & 4 & 24.749 & 24.731 & 24.69 & 24.704 \\
\hline & 5 & 24.751 & 24.715 & 24.685 & 24.712 \\
\hline & 6 & 24.775 & 24.761 & 24.741 & 24.671 \\
\hline & 7 & 24.579 & 24.532 & 24.587 & 24.579 \\
\hline & 8 & 24.729 & 24.676 & 24.682 & 24.662 \\
\hline & 9 & 24.81 & 24.804 & 24.765 & 24.761 \\
\hline & 10 & 24.795 & 24.779 & 24.761 & 24.774 \\
\hline \multirow[t]{10}{*}{ Silicone } & 1 & 24.738 & 24.737 & 24.734 & 24.717 \\
\hline & 2 & 24.728 & 24.728 & 24.702 & 24.682 \\
\hline & 3 & 24.714 & 24.716 & 24.701 & 24.675 \\
\hline & 4 & 24.746 & 24.749 & 24.737 & 24.706 \\
\hline & 5 & 24.751 & 24.744 & 24.731 & 24.71 \\
\hline & 6 & 24.753 & 24.749 & 24.726 & 24.711 \\
\hline & 7 & 24.726 & 24.722 & 24.709 & 24.687 \\
\hline & 8 & 24.766 & 24.753 & 24.735 & 24.703 \\
\hline & 9 & 24.73 & 24.715 & 24.698 & 24.691 \\
\hline & 10 & 24.735 & 24.725 & 24.699 & 24.668 \\
\hline \multirow[t]{10}{*}{ Zinc oxide eugenol } & 1 & 24.704 & 24.644 & 24.638 & 24.612 \\
\hline & 2 & 24.71 & 24.666 & 24.64 & 24.608 \\
\hline & 3 & 24.706 & 24.663 & 24.649 & 24.622 \\
\hline & 4 & 24.672 & 24.662 & 24.613 & 24.599 \\
\hline & 5 & 24.72 & 24.648 & 24.638 & 24.602 \\
\hline & 6 & 24.68 & 24.641 & 24.567 & 24.566 \\
\hline & 7 & 24.691 & 24.654 & 24.64 & 24.625 \\
\hline & 8 & 24.722 & 24.671 & 24.635 & 24.617 \\
\hline & 9 & 24.736 & 24.665 & 24.624 & 24.611 \\
\hline & 10 & 24.781 & 24.649 & 24.655 & 24.627 \\
\hline
\end{tabular}

considering the time taken to carry interocclusal recording materials to distant laboratories or delay in articulation or remounting of the casts if required. These measurements provide an indication regarding the dimensional stability. Ten samples for each material were made using a die similar to ADA specification No.19 at four different centers in different geographic location. The die and the interocclusal record material assembly were placed in to the water bath of $32 \pm 10^{\circ} \mathrm{C}$ to stimulate the oral temperature. Specimens having $3 \mathrm{~mm}$ thickness were considered for measurement because the accuracy may vary with time intervals and at different thickness. Travelling microscope was chosen for the measurement as per the testing methodology for ADA specification No.19. The results were obtained and Statistical analysis was performed using analysis of variance (ANOVA) and Tukey's Honestly Significant Difference (HSD) test for comparison among groups at the 0.05 level of significance (Tables 2, 3, 4). Group A (polyether) presented the least linear changes of all the material tested, at all-time intervals followed by group B (polyvinylsiloxane) and group C (zinc oxide eugenol$\mathrm{ZOE})$ respectively.

\section{Results}

The Figure- 6 shows the comparison of dimensional stability of three interocclusal recording materials at different hours using ANOVA. The standard deviation 
Table 2 Showing the comparison of the distance between horizontal lines at different time intervals for three interocclusal recording materials using ANOVA

\begin{tabular}{|c|c|c|c|c|}
\hline Hours Materials & 1Hours & 24Hours & 48Hours & 72 Hours \\
\hline & Mean \pm SD & Mean \pm SD & Mean \pm SD & Mean \pm SD \\
\hline Polyether & $24.740 \pm 0.068$ & $24.716 \pm 0.082$ & $24.707 \pm 0.056$ & $24.691 \pm 0.065$ \\
\hline Silicone & $24.739 \pm 0.015$ & $24.734 \pm 0.014$ & $24.717 \pm 0.017$ & $24.695 \pm 0.017$ \\
\hline ZnOE & $24.705 \pm 0.020$ & $24.656 \pm 0.010$ & $24.626 \pm 0.024$ & $24.607 \pm 0.017$ \\
\hline ANOVA & $F=0.93 p=0.44, N S$ & $F=3.42 p<0.05, S$ & $F=6.35 p<0.05, S$ & $F=6.36 p<0.05, S$ \\
\hline
\end{tabular}

$\mathrm{p} \leq 0.05$-significant(S), $\mathrm{p} \leq 0.001$-highly significant(HS), $\mathrm{p}>0.05$-not significant(NS).

(Table 1) with mean percentage of dimensional change for polyether at $1^{\text {st }}$ hour is $0.068(0.011 \%)$, at 24 hours is $0.082(0.0125 \%)$, at 48 hours is $0.56(0.0127 \%)$ and at 72 hours is $0.65(0.0133 \%)$ whereas polyvinylsiloxane at $1^{\text {st }}$ hour $0.015(0.012 \%)$, at 24 hours is $0.014(0.014 \%)$, at 48 hours is $1.017(0.015 \%)$ and at 72 hours is 1.017 $(0.016 \%)$ and Zincoxide eugenol at $1^{\text {st }}$ hour is 0.020 $(0.012 \%)$, at 24 hours is $0.010(0.015 \%)$, at 48 hours is $0.024(0.018 \%)$ and at 72 hours is $1.017(0.020 \%)$ indicating the dimensional stability of polyether is better than other two materials. The results shows (Table 2, Table 3, and Table 4 ) significant difference between the dimensional stability of all three material at different intervals with $\mathrm{p}$-value $<0.05$. Comparatively the polyether bite registration material showed less distortion with good dimensional stability compared to Poly vinyl siloxane bite (Jetbite), Zinc oxide eugenol(ZOE) bite (Super bite) at 1 hour, 24, 48, and 72 hours.

\section{Discussion}

The introduction of different interocclusal recording materials has put clinicians in dilemma that which material should be used in routine clinical practice for precise recording and transferring of accurate existing occlusal records for articulation of patient's diagnostic or working casts in the fabrication of good satisfactory prosthesis.

Hence, the present in-vitro study was planned to compare the time dependent dimensional stability of three interocclusal recording materials at 1 hour, 24, 42 and 72 hours with commonly used ZOE bite registration material in multicenter with wide area of geography with different level of experience in the field of dentistry to reduce the bias. The geography will play important role in its transport, storage and even in manipulation of the same material at different temperatures in true clinical situation in the Indian scenario. The operator skill is paramount in the manipulation of material as the other faculty of dentistry leaving prosthodontics also involved in this study to know the variations in the skill for manipulation of material for its usage. Dimensional stability can be studied in all the three planes by using equipment's like condymeter [8], computer axiotran, buhnergraph [10] and hydro-optic test measurement system.

Zincoxide eugenol is a traditional bite registration paste which is being used for a long time and has gained wide acceptance as impression as well as bite registration material because of its ease of manipulation and economy [19-25]. In this study ZOE expressed more dimensional change with passage of time i.e. $0.016 \%$ and continued to show drastic change over a period of 72 hours $1.017 \%$. The results of this study seem to be in accordance with an experimental study by Michalakis K X, Pissiotis A, Anastasiadou [3] on physical properties of interocclusal recording media. ZOE undergoes continues contraction after 1 hour and continues to show significant dimensional change along with weight loss. This could be explained by fact that, the setting reaction of $\mathrm{ZOE}$ is basically acid base reaction resulting in salt formation [2,20-29]. Water formed during chelation reaction evaporates leading to weight loss and contraction over a period of time. However, the Balthazar - Hart Y et al. [26] states that eugenol free zinc oxide paste showed less dimensional change when compared to that of the eugenol. Other factors like immersion of these in different disinfectant solutions have been studied by many with changes in linear dimensional stability [28-33].

The results of polyvinyl Siloxane have shown significant change in dimensional stability after 24 hours

Table 3 Showing the comparison of dimensional stability between three interocclusal recording materials at different hours by using Mann Whitney test

\begin{tabular}{lccrr}
\hline Hours Materials & 1Hour & 24Hour & 48Hours & 72Hours \\
\hline Polyether- Silicone & NS & $\mathbf{p}=\mathbf{0 . 5 1}$ (NS) & $\mathbf{p}=\mathbf{0 . 5 8}$ (NS) & $p=0.86$ (NS) \\
Polyether - ZnoE & NS & $\mathbf{p}=\mathbf{0 . 0 4 8 ( N S )}$ & $\mathbf{p}=\mathbf{0 . 0 0 1}(\mathbf{S})$ & $p=0.003,(\mathrm{~S})$ \\
Silicone - ZnoE & NS & $p=0.000<0.001(\mathrm{HS})$ & $p=0.000<0.001(\mathrm{HS})$ & $p=0.000 p<0.001(\mathrm{HS})$ \\
\hline
\end{tabular}

$\mathrm{p} \leq 0.05$-significant(S), $\mathrm{p} \leq 0.001$-highly significant(HS), $\mathrm{p}>0.05$-not significant(NS). 
Table 4 Showing the comparison of dimensional stability of three interocclusal recording materials at different hours using ANOVA

\begin{tabular}{lccr}
\hline Materials Hours & Polyether Mean \pm SD & Silicone Mean \pm SD & ZnOE Mean \pm SD \\
\hline 1Hour & $\mathbf{2 4 . 7 4 0 \pm 0 . 0 6 8}$ & $\mathbf{2 4 . 7 3 9 \pm 0 . 0 1 5}$ & $24.705 \pm 0.020$ \\
24Hour & $\mathbf{2 4 . 7 1 6 \pm 0 . 0 8 2}$ & $\mathbf{2 4 . 7 3 4 \pm 0 . 0 1 4}$ & $24.656 \pm 0.010$ \\
48Hour & $\mathbf{2 4 . 7 0 7} \pm \mathbf{0 . 0 5 6}$ & $\mathbf{2 4 . 7 1 7} \pm \mathbf{0 . 0 1 7}$ & $24.626 \pm 0.024$ \\
72Hour & $\mathbf{2 4 . 6 9 1 \pm 0 . 0 6 5}$ & $\mathbf{2 4 . 6 9 5 \pm 0 . 0 1 7}$ & $24.607 \pm 0.017$ \\
ANOVA & $F=0.911 p=0.45$ NS & $F=15.5 p<0.05 S$ & $F=55.92, p<0.05 S$ \\
\hline
\end{tabular}

$\mathrm{p} \leq 0.05$-significant(S), $\mathrm{p} \leq 0.001$-highly significant(HS), $\mathrm{p}>0.05$-not significant(NS).

$(0.15 \%)$. This result is in accordance with the finding of Michalakis $\mathrm{K}$ et al. [3] were dimensional stability of elastomeric materials showed $0.18 \%$ dimensional change after 24 hours and significant change in dimensional stability even after 168 hours. The reason might be that polyvinyl siloxane has longer polymerization period resulting in sustained contraction period. That silicone bite registration paste undergoes sustained contraction even after 72 hours $(0.016 \%)$.

In our study Polyether showed a $0.0125 \%$ dimensional change at 24 hours and with passage of time there is no much significant dimensional change ie $0.0127 \%$ on 48 hours. Change in the dimension was within the group of the ADA specification no.19 suggested value of $0.5 \%$ at 24 hours. Polyether bite registration is getting popular because of its dimensional stability. Our results are in accordance with Yvonne Balthazar, Sandrik J. [26], and Malone W.F.P, which showed that polyether exhibited no dimensional change after 24 hours [12]. Craig and peyton explains that Polyether sets by polymerization

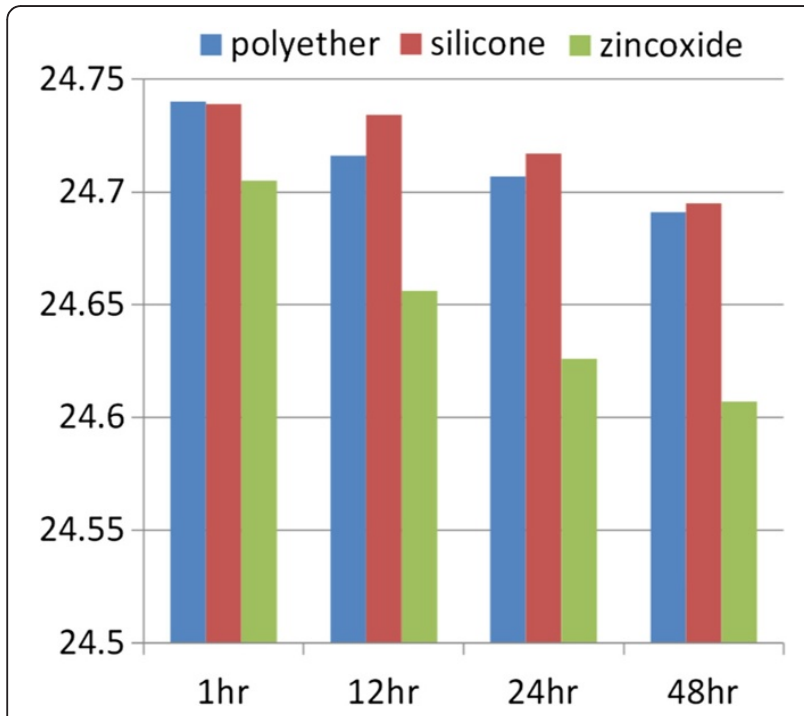

Figure 6 Showing the comparison of dimensional stability of three interocclusal recording materials at different hours using ANOVA. reaction so there will be volumetric shrinkage of the material during the reaction of about $0.3 \%[2,8,19,34]$.

\section{Conclusions}

It is mandatory to choose a material not only depending on the clinical situation but also based on the time taken for the articulation. The dimensional stability decreased with increase in time and is influenced by both material factor and time factor. Polyether was found to be more dimensionally stable interocclusal recording material, which was followed by Silicone and Zinc oxide eugenol. The dimensional stability of Polyether is good. Zinc oxide eugenol is dimensionally more unstable when compared with polyether and polyvinyl siloxane. Even the cost effectiveness and superiority of quality of material and its ease of manipulation is very important factor which governs the selection of the material. We recommend that the polyether interocclusal records must be articulated within 48 hours and Polyvinylsiloxane interocclusal records must be articulated within 24 hours and the ZOE should be articulated within 1-hour to get a correct restoration to have very minimum distortion and maximum satisfaction without failure of prosthesis.

Competing interests

The authors declare that they have no competing interests.

\section{Authors' contributions}

VSK, KCK and TSKB conceived of the study, and participated in its design and coordination and helped to draft the manuscript. The multicenter study carried out and reporting done by (1) VSK\& KCK, (2) TSKB (3) PDD, and (4) AKG with SN. The compilation of article was done by AKG and VSK with literature search and review done by TSKB \& PDD. The interpretation of data and analysis was carried out by SN, VSK and KCK. All authors read and approved the final manuscript.

\section{Author details}

${ }^{1}$ Principal Gandhi Dental College, Bubaneswar, India. ${ }^{2}$ Department of Conservative and Endodontics, Saraswati Dhanwantari Dental College and Hospital, Parbhani, (MS) 431401, India. ${ }^{3}$ Department of oral and maxillofacial Surgery, Saraswati Dhanwantari Dental College and Hospital, Parbhani, Pathri road, NH222, Parbhani, Maharashtra, India. ${ }^{4}$ Department of Conservative and Endodontics, Gurunanak institute of dental science \& research, Panihati, Kolkata 114, India. ${ }^{5}$ Department of Prosthodontics, SVS Institute of Dental Sciences, Mahaboobnagar, AP, India. ${ }^{6}$ Department of Prosthodontics, Saraswati Dhanwantari Dental College and Hospital, Parbhani, Pathri road, $\mathrm{NH} 222$, Parbhani, Maharashtra, India. ${ }^{7}$ Department of oral and maxillofacial Surgery, Saraswati Dhanwantari Dental College and Hospital, Parbhani, Pathri road, NH222, Parbhani, Maharashtra, India. 
Received: 20 July 2012 Accepted: 19 September 2012

Published: 5 October 2012

\section{References}

1. Michalakis KX, Pissiotis A, Anastasiadou V, Kapori D: An experimental study on particular physical properties of several Interocclusal recording media. Part II: Linear Dimensional change. J Prosthodont 2004, 13:150-159.

2. Anusavice: Philips science of Dental materials. Eleventhth edition. India: Saunders Publication; 2003

3. Michalakis KX, Pissiotis A, Anastasiadou V, Kapori D: An Experimental Study on Particular Physical Properties of Several Interocclusal Recording Media. Part I: Consistency Prior to Setting. J Prosthodont 2004, 13:42-46.

4. Freilich MA, Altieri JV, Wahle JJ: Principles for selecting Interocclusal records for articulation of dentate and partially dentate casts. J Prosthet Dent 1992, 68:361-367.

5. Berman MH: Accurate interocclusal records. J Prosthet Dent 1960, 10:620.

6. Shanahan TEJ, Leff A: Interocclusal records. J Prosthet dent 1960, 10:842-848.

7. Harry S: Accurate interocclusal records. J prosthet Dent 1969, 21(2):154-165.

8. Lassila V: Comparison of five interocclusal recording materials. $J$ Prosthet Dent 1986, 55(2):215-216.

9. Millstein PL, Clark RE, Myerson RL: Differential accuracy of silicone body interocclusal records and associated weight loss due to volatiles. J Prosthet Dent 1975, 33:649-654.

10. Eames WB, Wallace SW, Suway NB, Rogers LB: Accuracy and dimensional stability of elastomeric impression materials. J Prosthet Dent 1979, 42:159-162.

11. Mullick SC, Stackhouse JA, Vincent GR: A study of interocclusal record materials. J Prosthet Dent 1981, 46:304-307.

12. Fattore L, Malone WF, Sandrik JL, Mazur B, Hart T: Clinical evaluation of the accuracy of interocclusal recording materials. J Prosthet Dent 1984 51:152-157.

13. Lassila V, Mccabe JF: Properties of Interocclusal registration materials. J Prosthet Dent 1985, 53:100-104.

14. Millstein PL, Hsu C: Differential accuracy of elastomeric recording materials and associated weight change. J Prosthet Dent 1994, 71:400-403

15. Ursterin M, Moskona D, Cardash HS: A clinical evaluation of materials used in registering interjaw relationship. J Prosthet Dent 1991, 65:372-377.

16. Breeding LC, Dixon DL, Kinderknecht KE: Accuracy of three interocclusal recording materials used to mount a working cast. J Prosthet Dent 1994, 71:265-270.

17. Chai J, Tan E, Pang I: A study of the surface hardness and dimensional stability of several intermaxillary registration materials. Int J Prosthodont 1994, 7:538-542

18. Tripodakis AP, Vergos VK, Andreas G: Evaluation of the accuracy of interocclusal records in relation to two recording techniques. J Prosthet Dent 1997, 77:141-146.

19. Dixon LA: Overview of articulation materials and methods ofr the prosthodontics patient. J Prosthet Dent 2000, 83:235-247.

20. Ockert-Eriksson G, Eriksson A, Lockowandt P, Eriksson O: Materials for interocclusal records and their ability to reproduce a 3-dimensional jaw relationship. Int J Prosthodont 2000, 13(2):152-158.

21. de Oliveria Pagnano $V$, et al: A clinical evaluation of materials for interocclusal registration in centric relation. Braz Dent J 2000, 11(1):41-47.

22. Eriksson, et al: Clinical factors and clinical variation influencing the reproducibility of interocclusal recording methods. BDJ 2002, 92(7):395-400

23. Vassilis K, Vergos, Ari-Petros D, Tripodakis: Evaluation of vertical accuracy of interocclusal records. Int J Prosthodont 2003, 16:365-368.

24. Sonune $S$, Dange $S$, Khalikar A: An accurate interocclusal record by creating vertical stop. J Prosthodont 2005, 5(3):119-121.

25. Dua $P$, et al: Evaluation of four elastomeric interocclusal recording materils. MJAFI 2007, 63:237-240.

26. Balthazar-Hart Y, Sandrik JL, Malone WFP, Mazur B, Hart T: Accuracy and dimensional stability of four interocclusal recording materials. J Prosthet Dent 1981, 45:586-590

27. Muller J, Gotz G, Horz W, Kraft E: Study of the accuracy of different recording materials. J Prosthet Dent 1990, 63:41-46.

28. Breeding Larry C, Dixon DL: Compression resistance of four interocclusal recording materials. J Prosthet Dent 1992, 68:876-878.
29. Gelson Luis Adaba E: Effect of disinfectant agents on dimensional stability of elastomeric materials. J Prosthet Dent 1999, 8:1621-624.

30. Tomislav Ivanis J: Dimensional stability of elastomeric impression materials disinfected in a solution of $0.5 \%$ cholorohexidine gluconate and alcohol. Acta Stomatol Croat 2000, 34:11-14.

31. Taylor $\mathrm{RL}$, et al: Disinfection procedures their effect on the dimensional accuracy and surface quality of irreversible hydrocolloid impression materials and gypsum casts. Dental materials 2002, 18:103-110.

32. Silva SMLMD, Salvador MCG: Effect of the disinfection technique on the linear dimensional stability of dental impression materials. J Appl Oral Sci 2004, 12(3):244-249.

33. Melilli D, Rallo A, Caesaro A: The Effect of immersion disinfection procedures on dimensional stability of two elastomeric impression materials. Journal of Oral Science 2008, 50:441-446.

34. Sunneta B, Gangadhar SA: Comparison of compressive resistance among the Elastomeric Interocclusal recording material. JIDA 2011, 5:710-714.

doi:10.1186/1746-160X-8-27

Cite this article as: Tejo et al:: A comparative evaluation of dimensional stability of three types of interocclusal recording materials-an in-vitro multi-centre study. Head \& Face Medicine 2012 8:27.

\section{Submit your next manuscript to BioMed Central and take full advantage of:}

- Convenient online submission

- Thorough peer review

- No space constraints or color figure charges

- Immediate publication on acceptance

- Inclusion in PubMed, CAS, Scopus and Google Scholar

- Research which is freely available for redistribution 